\title{
AMPLIAÇÃO DOS PRINCÍPIOS CONSTITUCIONAIS PROCESSUAIS NO RECURSO DE AGRAVO DE INSTRUMENTO
}

\section{EXPANSION OF THE CONSTITUTIONAL PROCEDURAL PRINCIPLES IN THE APPEAL OF INTERLOCUTORY APPEAL}

\author{
Ana Luisa de Figueiredo Guimarães* \\ Ester Moraes D'Avila**
}

\begin{abstract}
RESUMO
O objetivo deste artigo é analisar o recurso do agravo de instrumento tendo por base o conceito da taxatividade mitigada na sustentação oral e na possibilidade de se ter um recurso adesivo. Essa mitigação, embora em algumas situações, como será visto nesse estudo, é questionável, é, contudo, em regra, consistente com o princípio constitucional processual do contraditório e da ampla defesa, que se pautam no princípio basilar do devido processo legal. Além disso, o artigo realiza um comparativo entre o Código de Processo Civil de 1973 e 2015, ressaltando as principais modificações. Por meio das jurisprudências do Tribunal de Justiça do Distrito Federal e dos Territórios e o de Minas Gerais, analisar-se-á os seus posicionamentos acerca das temáticas a serem tratadas. Percebe-se que a sustentação oral e o agravo de instrumento na forma adesiva não são matérias pacificadas, o que, consequentemente, acarreta na insegurança jurídica. Assim, necessita-se de uma mudança na interpretação hermenêutica das normas processuais.
\end{abstract}

Palavras-chave: Agravo de Instrumento. Sustentação oral. Código de Processo Civil. Taxatividade mitigada. Princípios constitucionais processuais.

\begin{abstract}
The aim of this article is to analyze the resource of instrument aggravation based on the concept of mitigated taxactivity in oral support and the possibility of having an adhesive feature. This mitigation, although in some situations, as will be seen in this study, is questionable is, however, as a rule, consistent with the procedural constitutional principle of adversarium and broad based on the basic principle of due process. In addition, the article makes a comparison between the Code of Civil Procedure of 1973 and 2015, highlighting the main modifications. Through the jurisprudence of the Court of Justice of the Federal District and Territories and that of Minas Gerais, will be analyzed their positions on the topics to be addressed It is perceived that oral support and the aggravation of an instrument in the adhesive form are not pacified materials, which, consequently, leads to legal uncertainty. Thus, a change in the hermeneutic interpretation of procedural norms is needed.
\end{abstract}

\footnotetext{
* Graduanda do curso de direito da Pontifícia Universidade Católica de Minas Gerais. Monitora de Direito Civil Parte Geral no $2^{\circ}$ semestre de 2019 e $1^{\circ}$ e $2^{\circ}$ semestre de 2020 e de Direito Civil Obrigações e Responsabilidade e Direito Civil II no $1^{\circ}$ semestre de 2021. Pesquisadora de Iniciação Científica em Direito Civil. E-mail: analuisafigueiredo@outlook.com.

** Graduanda do curso de direito da Pontifícia Universidade Católica de Minas Gerais. Monitora de Direito Constitucional I e II no $2^{\circ}$ semestre de 2020. Pesquisadora de Iniciação Científica em Direito Civil. E-mail: estermoraess07@gmail.com
} 
Key-words: Interlocutory appeal. Oral support. Civil Procedure Code. Mitigated taxactivity. Constitutional procedural principles.

\section{INTRODUÇÃO}

O agravo de instrumento é um recurso que possibilita a recorribilidade das decisões interlocutórias no processo. Tem-se como regra geral o princípio da irrecorribilidade das interlocutórias de imediato, ou seja, o conteúdo da decisão será discutido no recurso de apelação ou nas contrarrazões, em conjunto com o da sentença. Porém, em caráter excepcional, existem interlocutórias que podem ser recorríveis de imediato, utilizando-se do agravo de instrumento.

No Código de Processo Civil de 1973 (CPC/73) havia a previsão de duas modalidades de agravo, quais sejam, o agravo retido, que era a regra, e o de instrumento, a exceção. $\mathrm{O}$ agravo retido deveria ser interposto perante o juízo que deferiu a decisão interlocutória e apenas após a sentença, por meio da apelação, que haveria a possibilidade de o agravo retido ser encaminhado para análise do tribunal. Já os requisitos para manejar o agravo de instrumento equiparam-se aos da tutela provisória. Isso se deve, pois, se a decisão causasse uma situação emergencial para a parte, ou seja, um perigo de dano dado ao caráter de urgência, não faria sentido manejar um recurso que ficaria retido, o qual só seria analisado se houvesse uma apelação ou contrarrazões. Por isso, diante de situações emergenciais, neste Código, caberia agravo de instrumento. Nesse sentido afirma DONIZETTI (2018, p. 996):

\footnotetext{
No regime do CPC/1973, com relação ao agravo de instrumento, a taxatividade era prevista apenas para os casos de inadmissão da apelação e para os relativos aos efeitos em que a apelação era recebida. Fora disso, para cabimento da forma instrumental do agravo, era preciso demonstrar que a decisão recorrida era suscetível de causa à parte lesão grave e de difícil reparação. Não admitida a forma instrumental para impugnar a decisão, o agravo retido era a solução.
}

Atualmente, pela ótica do Código de Processo Civil de 2015 (CPC/15), não se tem mais a figura do agravo retido, restando apenas o agravo de instrumento, o qual possui um rol previsto no art. 1015. Existem três correntes que dissertam sobre a taxatividade deste. Uma das correntes alega que o rol seria exaustivo, quanto a segunda, com maior quantidade de adeptos defende a taxatividade, que admite interpretações analógicas ou extensivas, já a terceira afere que o rol é exemplificativo. O Superior Tribunal de Justiça (STJ) já pacificou essa tese ao tratar da taxatividade mitigada, que será vista adiante. Acerca dessa divergência doutrinária e jurisprudencial, a Ministra Nancy Andrighi afirmou que:

De início, expôs que parte da corrente doutrinária argumentava que o rol seria absolutamente taxativo, vez que o Código de Processo Civil buscou trazer um rol fechado, objetivando descarregar o judiciário e evitar recursos meramente protelatórios, alegando ainda que não poderia ser ampliada a interpretação do instituto pois causaria comprometimento de todo o sistema eleito pelo CPC.

Em segunda ordem de questionamento, revelou que outra parte da doutrina vinha formalizando entendimento de que o rol poderia admitir uma interpretação extensiva, haja vista que algumas hipóteses não abarcadas pelo rol do agravo de instrumento, causariam graves danos, nos casos em que fossem decididas questões de urgência, por exemplo, questões de incompetência, sigilo processual, entre outras.

Por último, argumentou que outro terço da doutrina, defendia que o rol não era nem taxativo de forma fechada ou taxativo de interpretação extensiva, mas sim, um rol meramente exemplificativo, de modo que, a recorribilidade da decisão interlocutória, 
deveria ser imediata, ainda que a matéria não constasse nos incisos do art. 1.015 do $\mathrm{CPC}^{1}$.

Dessa forma, percebe-se a existência de três correntes doutrinárias acerca da temática, porém, como exposto anteriormente, não há um consenso, como bem afirmou a Ministra Nancy Andrighi, a corrente defensora de um rol taxativo possui maior aderência, a fim de evitar insegurança jurídica e resguardar o princípio da celeridade processual.

\title{
2 PRINCÍPIOS CONSTITUCIONAIS PROCESSUAIS REFERENTES AO AGRAVO DE INSTRUMENTO
}

Os princípios constitucionais que sustentam as atividades processuais, enunciados, majoritariamente, no artigo $5^{\circ}$ da Constituição, têm por objetivo direcionar o posicionamento dos tribunais e auxiliar os juízes dentro de suas atividades normativas, a partir da lógica do Devido Processo Legal, conceituado por DIAS e et al (2016, p. 48):

\begin{abstract}
Um bloco aglutinante e compacto de vários direitos e garantias fundamentais inafastáveis ostentados pelas pessoas do povo, quando deduzem pretensão à tutela jurídica como parte nos processos, perante os órgãos jurisdicionais do Estado, quais sejam: $1^{\circ}$ direito de ação; $2^{\circ}$ garantia do juízo natural ou juízo constitucional; $3^{\circ}$ garantia da ampla defesa; $4^{\circ}$ garantia do contraditório paritário e participativo; $5^{\circ}$ garantia das fundamentais racionais das decisões jurisdicionais centrada na reserva legal.
\end{abstract}

Tal como afirmado pelo autor, o princípio do devido processo legal pode ser considerado como a base para a origem dos demais princípios, dentre eles, o contraditório e o da ampla defesa, os quais se relacionam diretamente com a temática deste artigo. Enunciados no art $5^{\circ}, \mathrm{LV}$ da Constituição Federal:

Art $5^{\circ} \mathrm{LV}$ - aos litigantes, em processo judicial ou administrativo, e aos acusados em geral são assegurados o contraditório e ampla defesa, com os meios e recursos a ela inerentes

O princípio do contraditório visa a participação das partes na construção do processo, por meio da possibilidade de influenciar a decisão do juízo competente e pode estar presente em todas as fases processuais, em especial, na recursal. Já a ampla defesa relaciona-se diretamente com o princípio da não surpresa e é garantido a partir dos meios de defesa, dentre eles os recursos, nos quais se incluem o direito à prova e à assistência técnica de um advogado público ou privado ou a defensoria pública.

Nesse sentido, o agravo de instrumento é um recurso que deve observância aos princípios supramencionados, porém, deve-se destacar que, quanto à sustentação oral, esses princípios não são aplicados devidamente, temática discutida na jurisprudência.

\section{TEORIA DA TAXATIVIDADE MITIGADA}

Em relação às correntes que defendem o rol taxativo ou exaustivo do art. 1015 do CPC/15, o Superior Tribunal de Justiça foi de encontro ao primeiro e alegou ainda que haveria

\footnotetext{
${ }^{1}$ BARBOSA, Renan Costa. A teoria da taxatividade mitigada no rol de cabimento do agravo de instrumento. Revista Jus Navigandi, ISSN 1518-4862, Teresina, ano 24, n. 5872, 30 jul. 2019. Disponível em: https://jus.com.br/artigos/75533. Acesso em: 9 jul. 2020.
} 
uma taxatividade mitigada. Segundo esta, todas as vezes que a interlocutória gerar uma situação emergencial à parte (dano grave ou de difícil reparação), será recorrível de imediato. Isso se dá pois a morosidade do julgamento pode causar danos irreversíveis à parte, então se admite essa possibilidade. Afere THEODORO JÚNIOR (2019. p. 1027):

Sem embargo das ponderações ora feitas, a questão foi apreciada, com força de uniformização da jurisprudência, pela Corte Especial do STJ, resultando nas seguintes conclusões:

(a) Não é aceitável a tese de que o rol do art. 1.015 do CPC seria meramente exemplificativo, porque "resultaria na repristinação do regime recursal das interlocutórias que vigorava no $\mathrm{CPC} / 73$ e que fora conscientemente modificado pelo legislador do novo CPC", de modo que, ao adotá-la, "estaria o Poder Judiciário substituindo a atividade e a vontade expressamente externada pelo Poder Legislativo". (b) Entretanto, a taxatividade absoluta do rol do art. 1.015 seria incompatível com as normas fundamentais do processo civil, "na medida em que sobrevivem questões urgentes fora da lista do art. 1.015 do CPC" e que tornam inviável sua interpretação restritiva.

(c) Nos termos do art. 1.036 e seguintes do CPC/2015, foi fixada a seguinte tese jurídica: "O rol do art. 1.015 do CPC é de taxatividade mitigada, por isso admite a interposição de agravo de instrumento quando verificada a urgência decorrente da inutilidade do julgamento da questão no recurso de apelação". Estabeleceu-se, outrossim, "um regime de transição que modula os efeitos da presente decisão, a fim de que a tese jurídica somente seja aplicável às decisões interlocutórias proferidas após a publicação do presente acórdão"2

Porém, tem-se uma discussão acerca da efetividade da taxatividade mitigada, pois, a hipótese de cabimento se relaciona com a tutela provisória, que já está prevista no próprio artigo 1015, I do Código de Processo Civil. Isso significa que não há mitigação quando se tem o "periculum in mora", isto é, uma situação emergencial, ou um direito inequívoco.

\section{ADMISSIBILIDADE DO AGRAVO DE INSTRUMENTO QUANTO À SUSTENTAÇÃO ORAL E A POSSIBILIDADE DE RECURSO ADESIVO}

Após compreender os princípios inerentes ao direito processual, que devem se adequar ao agravo de instrumento, bem como a qual pronunciamento judicial - decisão interlocutória este é cabível, vale analisar a possibilidade de sustentação oral dessa forma recursal e do recurso adesivo.

A sustentação oral consiste em uma forma de defesa, em que o advogado sustenta as razões de seu recurso ou as suas contrarrazões perante o juízo competente. O agravo de instrumento é uma espécie recursal que não admite a possibilidade da sustentação oral, salvo na hipótese do artigo 937 do Código de Processo Civil de 2015 como menciona THEODORO JÚNIOR (2019, p. 736):

Na sessão de julgamento, os advogados e o membro do Ministério Público, nos casos de sua intervenção, poderão nos casos previstos em lei ou no regimento interno do tribunal, fazer sustentação oral de suas razões, pelo prazo improrrogável de quinze minutos cada, depois da exposição da causa pelo relator (art. 937). O CPC/2015 (art. 937) enumera os seguintes casos de cabimento da sustentação oral:

(a)recurso de apelação (inciso I);

(b)recurso ordinário (inciso II);

(c)recurso especial (inciso III);

\footnotetext{
${ }^{2}$ STJ, Corte Especial, REsp 1.704.520/MT, Recurso repetitivo - tema 988, Rel. Min. Nancy Andrighi, ac. 05.12.2018, DJe 19.12.2018.
} 


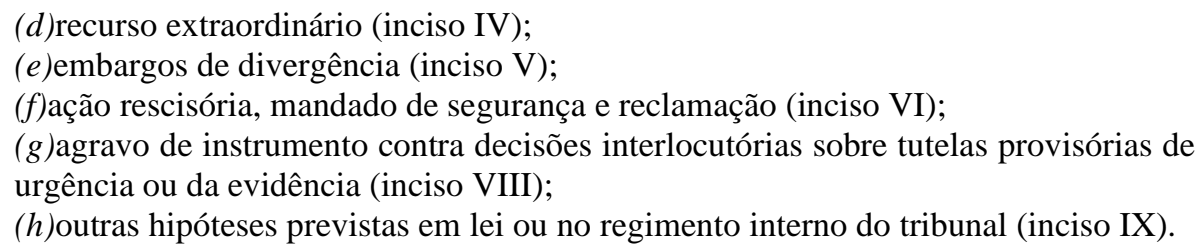

Assim, como as hipóteses do art. 937 do código supramencionado são taxativas, não haveria interpretação extensiva de sustentação oral para mais situações cabíveis de agravo de instrumento. Todavia, a exceção se encontra na tutela provisória prevista no art. 1015, I, caracterizando uma mitigação. Uma possível crítica derivada dessa limitação se dá no caso das interlocutórias que versem sobre o mérito, pois se assemelham ao recurso de apelação, e neste é possível a sustentação oral, mencionada no art. 937, I, de forma ampla e sem limitações. Tal determinação normativa se dá a fim de cumprir o princípio do devido processo legal, em especial, a ampla defesa. WAMBIER e et al afirmam que:

Embora o NCPC não tenha sido expresso, é de se admitir sustentação oral nos casos em que a decisão, embora recorrível por meio de agravo, tenha conteúdo de sentença, como é o caso, por exemplo, da decisão que põe fim à liquidação de sentença.

Alega, ainda, Daniel Amorim Assunção Neves (2015, p. 476-477):

Há nesse rol uma inexplicável omissão. A partir do momento em que o Novo CPC consagra as decisões interlocutórias de mérito, recorríveis por agravo de instrumento, como não se admitir nesse caso a sustentação oral das partes? Tome-se como exemplo o art. 356 do Novo CPC, que consagra o julgamento antecipado parcial do mérito e em seu $\S 5^{\circ}$. Prevê expressamente a recorribilidade por agravo de instrumento. Julgado todo o mérito antecipadamente, caberá apelação e, nos termos do inciso I do art. 937 do Novo CPC, será permitida a sustentação oral. Mas julgada apenas parcela desse mérito, não caberá sustentação oral do recurso interposto pela parte sucumbente? É óbvio que, havendo um Novo CPC, o ideal seria a previsão expressa de cabimento de sustentação oral em agravo de instrumento contra decisão interlocutória de mérito. A injustificada e incompreensível omissão legislativa, entretanto, não é capaz de afastar esse direito das partes, bastando para fundar tal conclusão uma interpretação extensiva das hipóteses de cabimento. Ora, se é cabível sustentação oral em apelação interposta contra sentença terminativa, como impedi-la em agravo de instrumento interposto contra decisão de mérito?”

Dessa forma, quando o agravo de instrumento chega no Tribunal, não admite sustentação oral, conforme o artigo supracitado. Entretanto cabe a análise prévia do regimento interno de cada Tribunal, pois alguns deles se fixam no entendimento da taxatividade mitigada e podem admitir a sustentação oral. Exemplo disso é o regimento do Tribunal de Justiça de Minas Gerais, o qual afere no art. 105:

Art. 105. Poderá haver sustentação oral pelo prazo de 15 (quinze) minutos para cada uma das partes e o Ministério Público, na condição de fiscal da lei, ressalvados os prazos especiais fixados em lei: (Redação dada pela Emenda Regimental n ${ }^{\circ}$ 6, de 2016) (...)

II - nos agravos de instrumento e interno de decisão que: (Redação dada pela Emenda Regimental $n^{\circ} 6$, de 2016)

a) versar sobre tutelas provisórias de urgência ou da evidência; (Redação dada pela Emenda Regimental n 6, de 2016)

b) decretar falência ou deferir o pedido de recuperação judicial; (Redação dada pela Emenda Regimental n 6, de 2016)

c) decretar prisão civil; 
d) pronunciar a prescrição ou a decadência;

e) julgar monocraticamente a apelação ou o reexame necessário.

De acordo com a norma mencionada, é possível ressaltar que se teve uma elasticidade das hipóteses de sustentação oral, de forma que uma dessas é meritória, qual seja, "pronunciar a prescrição e decadência".

Já quanto à temática do recurso adesivo, este está subordinado ao juízo de admissibilidade positivo do recurso principal. Isso significa que o principal deve ser conhecido para que o adesivo também seja. Porém, o conhecimento por si só não é suficiente, deve-se observar todos os requisitos de admissibilidade - extrínsecos e intrínsecos. Dessa forma, a sucumbência é recíproca e o código permitiu que, mesmo com a perda de prazo processual para interposição de recurso independente, fosse possível recorrer de forma adesiva. Atesta THEODORO JÚNIOR (2019, p. 955):

Uma exceção à regra da preclusão consumativa ocorre na sucumbência recíproca, porque a lei permite à parte, que não recorreu no prazo normal, valer-se do prazo de contrarrazões para manifestar recurso adesivo ao do adversário (CPC/2015, art. 997, $\S \S 1^{\mathrm{o}}$ e $\left.2^{\mathrm{o}}\right)$.

Porém, tem-se uma divergência doutrinária quanto ao cabimento do recurso adesivo em agravo de instrumento interposto em decisão interlocutória, em sede de julgamento antecipado parcial do mérito, na hipótese do inciso II, do art. 1015 do Código de Processo Civil de 2015. O mérito, a princípio, deve ser julgado na sentença, contudo, o juiz pode julgar o mérito antecipadamente, no curso do processo.

Quando se tratar de uma interlocutória que verse sobre o mérito, algumas correntes defendem que se equipara à apelação, portanto, cabendo a forma adesiva em sua interposição. Nesse contexto, afirma Rogéria Dotti:

Embora o art. 997, § $2^{\circ}$, II do Código autorize sua aplicação apenas nos casos de apelação, de recurso extraordinário e de recurso especial, não há dúvida que o recurso contra a decisão parcial de mérito também comporta esta interpretação extensiva. Por uma questão de coerência, deve-se então admitir o agravo de instrumento adesivo.

Dessa forma, não seria coerente que ao se ter um pedido controverso, a parte, por exemplo, aguardasse o trâmite processual. Assim, o juiz profere uma decisão interlocutória mista que julgue esse mérito parcialmente, de forma que se evite a morosidade processual $^{3} \mathrm{e}$ garante a efetividade do judiciário.

\section{JURISPRUDÊNCIA ACERCA DA TEMÁTICA}

Em relação a possibilidade de sustentação oral no recurso de agravo de instrumento, tem-se o seguinte julgado do Tribunal de Justiça do Rio de Janeiro:

EMBARGOS DE DECLARAÇÃO EM AGRAVO DE INSTRUMENTO. NULIDADE. SUSTENTAÇÃO ORAL. CERCEAMENTO DE DEFESA. O fato de não ter constado expressamente na certidão do julgamento do dia 19/09/2017 que o feito foi adiado para a sessão seguinte, nos termos do art. 935 do CPC, configura-se

\footnotetext{
${ }^{3}$ Segundo DIAS, “as manifestações de crítica e de insatisfação no tocante à jurisdição brasileira são de matrizes variadas, não somente em face da demora crônica em que lhe é prestada, mas também quanto à sua importante perspectiva institucional, as vezes negligenciada pelos seus órgãos [...]”. (DIAS, Ronaldo Brêtas de Carvalho. Processo Constitucional e Estado Democrático de Direito. $3^{\circ}$ Ed. Belo Horizonte: Del Rey, 2015 , p.199).
} 


\begin{abstract}
cerceamento de defesa, pois os agravantes, ora embargantes, não tiveram a oportunidade de realizar a sustentação oral, cabível na hipótese, nos termos do art. 937, VIII, do CPC, vez que trata de agravo de instrumento interposto contra decisão interlocutória que concedeu parcialmente a tutela de urgência. RECURSO PROVIDO COM EFEITOS INFRINGENTES PARA DECLARAR A NULIDADE DO ACÓRDÃO ATACADO, INCLUINDO-SE O FEITO EM PAUTA PARA JULGAMENTO DO AGRAVO DE INSTRUMENTO.
\end{abstract}

Neste, os agravantes interpuseram o embargo de declaração a fim de sanar a falta da sustentação oral, o que vai contra o disposto no art. 937 do CPC/15. A sessão de julgamento foi adiada sem que houvesse intimação da data da nova sessão, configurado o cerceamento da defesa, pois os agravantes, ora embargantes, não tiveram a oportunidade de realizar a sustentação oral, vez que se tratava de agravo de instrumento interposto contra decisão interlocutória que concedeu parcialmente a tutela de urgência.

O regimento interno do Tribunal de Justiça do Distrito Federal e dos Territórios prevê a possibilidade da sustentação oral nos agravos de instrumento que versem sobre o mérito:

Art. 110. Não comportarão sustentação oral as seguintes hipóteses: (Redação dada pela Emenda Regimental n ${ }^{\circ} 13$, de 2019).

I - agravos de qualquer espécie, exceto: (Redação dada pela Emenda Regimental $n^{\circ}$ 13, de 2019).

a) agravo de instrumento interposto contra decisão interlocutória que verse sobre tutela provisória de urgência ou da evidência; (Incluído pela Emenda Regimental $\mathrm{n}^{\circ}$ 13, de 2019).

b) agravo de instrumento interposto contra decisão que julgue antecipadamente parte do mérito; (Incluído pela Emenda Regimental nº 13, de 2019).

Nesse sentido o julgado a seguir mantém o posicionamento do artigo mencionado anteriormente, constatado no regimento interno, especificamente, no inciso I, alínea b:

CIVIL. AGRAVO DE INSTRUMENTO. AÇÃO DE DESPEJO. DENÚNCIA VAZIA. CONTRATO DE LOCAÇÃO POR PRAZO INDETERMINADO. AUSÊNCIA DE NOTIFICAÇÃO PARA DESOCUPAÇÃO VOLUNTÁRIA. AUSÊNCIA DE CONDIÇÃO DE PROCEDIBILIDADE DA AÇÃO.

1- Com a proximidade da entrada em vigor no NCPC (Lei 13.105), no dia 17 de março de 2016, de bom alvitre lembrar que o agravo de instrumento ficou mantido para as hipóteses de concessão, ou não, de tutela de urgência; para as interlocutórias de mérito; para as interlocutórias proferidas na execução (e no cumprimento de sentença) e para todos os demais casos a respeito dos quais houver previsão legal expressa, repetindo-se o mesmo sistema que o CPC de 1939 (art. 842). Objetivando alcançar resultado do processo mais perto da realidade dos fatos, previu-se a sustentação oral também em agravo de instrumento, onde se discuta decisão de mérito.

2- Agravo de instrumento interposto contra decisão proferida em ação de despejo, por denúncia vazia. 2.1. Na decisão agravada foi determinado o despejo liminar da agravante.

(...)

No que tange à jurisprudência acerca do agravo de instrumento adesivo, cabe analisar duas jurisprudências, a primeira do Tribunal de Justiça de Minas Gerais que não admite esse tipo de recurso na forma adesiva, e a segunda do Tribunal de Justiça do Distrito Federal e dos Territórios, o qual se mostra mais flexível e adota a ideia da taxatividade mitigada.

EMENTA: APELAÇÃO - INCIDENTE DE HABILITAÇÃO DE CRÉDITO EM INVENTÁRIO - NATUREZA INTERLOCUTÓRIA - PROVIMENTO AUTOINTITULADO COMO SENTENÇA - IRRADIAÇÃO DA EXPECTATIVA 
DE ACERTO NA INTERPOSIÇÃO DA APELAÇÃO - PRINCÍPIO DA FUNGIBILIDADE RECURSAL - CONHECIMENTO - RECURSO ADESIVO INSTITUTO QUE NÃO ABRANGE O AGRAVO DE INSTRUMENTO - NÃO CONHECIMENTO - FUNGIBILIDADE INAPLICÁVEL - DISCORDÂNCIA DOS HERDEIROS - LITIGIOSIDADE CONFIGURADA - REMESSA DO PLEITO ÀS VIAS ORDINÁRIAS - RESERVA DE BENS - SUCUMBÊNCIA RECÍPROCA RECURSO PRINCIPAL PARCIALMENTE PROVIDO

- A natureza interlocutória da decisão que julga o incidente de habilitação de crédito em inventário atrai o cabimento do agravo de instrumento como a via recursal adequada.

- Autointitulado o "decisum" como sentença, remanesce irradiada da prolatação a expectativa de acerto no manejo da apelação. Em consequência, deve ser conhecido o recurso, em aplicação concreta do princípio da fungibilidade.

- O princípio da fungibilidade recursal, ensejador do conhecimento da apelação embora cabível o agravo de instrumento, não se estende ao recurso adesivo, ante a inexistência dessa figura recursal no âmbito do inconformismo efetivamente previsto em lei.

- Resistida a pretensão de habilitação do crédito em inventário, tem-se por caracterizada a litigiosidade que justifica a fixação dos honorários de advogado. Todavia, a distribuição dos ônus sucumbenciais deve levar em conta a determinação de reserva de bens, o que atrai o parcial decaimento do réu.

- Recurso principal conhecido, por aplicação do princípio da fungibilidade, e parcialmente provido. Recurso adesivo não conhecido.

No julgado, o recurso adesivo não foi conhecido pois o tribunal pautou-se apenas no dispositivo legal do Código de Processo Civil, considerando-o taxativo, ao contrário do julgado posterior, do TJDFT, que admite a mitigação do rol trazido pelo referido dispositivo:

AGRAVO DE INSTRUMENTO. RECURSO ADESIVO. NÃO CABIMENTO. ASTREINTES. CRITÉRIO DE FIXAÇÃO. RAZOABILIDADE E PROPORCIONALIDADE. EFEITO COERCITIVO 1.O art. 997, §2 ${ }^{\circ}$ inciso II, CPC, limita as hipóteses de cabimento de recurso adesivo à apelação, recurso extraordinário e recurso especial; 2 . Somente seria admissível o recurso adesivo em agravo de instrumento se interposto em face de decisão proferida na forma prevista pelo art. 356, CPC, que admite a solução de mérito parcial quando formulado mais de um pedido e um ou mais deles mostrarem-se incontroversos e estivessem em condições de julgamento imediato.

(..)

Segundo o relator Romeu Gonzaga Neiva, seria admissível o recurso adesivo em agravo de instrumento que tratasse sobre o mérito da lide, visto que as hipóteses previstas do art. 997 do recurso adesivo importam, necessariamente, em um recurso interposto em face de decisão.

\section{CONCLUSÃO}

Após a compreensão da sustentação oral e do recurso adesivo quanto ao recurso do agravo de instrumento, percebe-se que não há consenso jurisprudencial acerca dessas temáticas. Porém, alguns tribunais estão adotando uma perspectiva mais inovadora quando comparado a outros tribunais mais conservadores, que se mantêm em uma postura menos flexível em relação ao disposto no Código de Processo Civil de 2015. Além disso, tal posicionamento pode levar ao descumprimento do princípio basilar do processo, qual seja o devido processo legal.

Por fim, deve-se observar o regimento interno de cada tribunal, nessas hipóteses estudadas no artigo, a fim de aplicar o que lhe é disposto. Vale mencionar que a divergência de entendimentos desses tribunais são causadores de uma instabilidade jurídica, por isso, é 
necessária uma discussão acerca dessas temáticas a fim de uniformizar a aplicação das normas e garantir a igualdade no âmbito processual.

\section{REFERÊNCIAS}

BRASIL, Lei n 13.105 de 16 mar. 2015. Código de Processo Civil. Brasília, em 16 mar. 2015. Disponível em: http://www.planalto.gov.br/ccivil_03/_ato2015-2018/2015/lei/113105.htm. Acesso em: 08 jul. 2020.

BRASIL, Tribunal de Justiça do Distrito Federal e dos Territórios. Regimento Interno, estabelecido pela Emenda Regimental $\mathrm{n}^{\circ} 13$, de 2019. Disponível em: https://www.tjdft.jus.br/publicacoes/regimentos/regimento-interno-do-

tjdft/regimentoInternoTJDFT.pdf. Acesso em: 08 jul. 2020.

BRASIL, Tribunal de Justiça de Minas Gerais, Regimento Interno, estabelecido pela Emenda Regimental $\mathrm{n}^{\circ}$ 6, de 26.04.2016. Disponível em: https://www.tjmg.jus.br/portal-tjmg/atosnormativos/regimento-interno.htm\#.XwOQtyhKjIU. Acesso em: 06 jul. 2020.

BRASIL, Constituição da República Federativa do Brasil de 1988. Nós representantes do povo brasileiro, reunidos em Assembléia Nacional Constituinte para instituir um estado democrático (...). Diário Oficial da União, Brasília, em 5 out. 1988. Disponível em: http://www.planalto.gov.br/ccivil_03/constituicao/constituicao.htm. Acesso em: 01 jul. 2020.

DIAS, Ronaldo Brêtas de Carvalho; SOARES, Carlos Henrique; BRÊTAS, Suzana Oliveira Marques; DIAS, Renato José Barbosa e BRÊTAS, Yvonne Mól. Estudo Sistemático do NCPC. Ed. D’Plácido. $2^{\circ}$ Ed. Belo Horizonte. 2016.

DONIZETTI, Elpídio. Novo Código de Processo Civil Comentado. $3^{\circ}$. ed. São Paulo. Atlas, 2018.

DOTTI, ROGÉRIA. Julgamento parcial de mérito. Jus Brasil. 2017. Disponivel em: https://processualistas.jusbrasil.com.br/artigos/480283183/julgamento-parcial-de-merito-nocpc-2015 . Acesso em: 07 jul. 2020.

Humberto, T. J. Curso de Direito Processual Civil - Vol. III. Rio de Janeiro; Grupo GEN, 12/2019. $9788530988838 . \quad$ Disponível em: https://integrada.minhabiblioteca.com.br/\#/books/9788530988838/. Acesso em: 06 Jul 2020.

NEVES, Daniel Amorim Assumpção, Novo código de processo civil, São Paulo: Método, 2015, p. 476-477.

TJ-DF - AGI: 20150020117538, Relator: JOÃO EGMONT, Data de Julgamento: 22/07/2015, $2^{a}$ Turma Cível, Data de Publicação: Publicado no DJE: 27/07/2015. Pág.: 173.

TJ-DF 07264588020198070000 DF 0726458-80.2019.8.07.0000, Relator: ROMEU GONZAGA NEIVA, Data de publicação: 11/03/2020, $7^{\circ}$ Turma Cível, Data de Publicação: Publicado no PJe: 28/04/2020. 
TJ-MG - Apelação Cível 1.0324.18.001633-3/001, Relator(a): Des.(a) Corrêa Junior, 6 ${ }^{\mathrm{a}}$ CÂMARA CÍVEL, julgamento em 09/06/2020, publicação da súmula em 19/06/2020.

TJ-RJ- AI: 00009562120178190000. Relator: Des(a). CARLOS AZEREDO DE ARAÚJO. Data de Julgamento: 05/07/2018, NONA CÂMARA CÍVEL.

WAMBIER, Teresa Arruda Alvim; CONCEIÇÃO, Maria Lúcia Lins; RIBEIRO, Leonardo Ferres da Silva e MELLO, Rogerio Licastro Torres de. Primeiros comentários ao novo código de processo civil. São Paulo: RT, 2015, p. 1333. 